http://jmscr.igmpublication.org/home/ ISSN (e)-2347-176x ISSN (p) 2455-0450 crossref DOI: https://dx.doi.org/10.18535/jmscr/v7i10.02

\title{
Analysis of Factors Affecting the Functional Outcome of Intra Articular Distal Femoral Fractures
}

\author{
Authors \\ Dr D Prasad Reddy ${ }^{1 *}$, Dr Rajkumar Angothu² \\ ${ }^{1}$ Assistant Professor, Department of Orthopedics, Kakatiya Medical College and MGM Hospital Warangal, \\ Telangana state \\ ${ }^{2}$ Senior Resident, Department of Orthopedics, Kakatiya Medical College and MGM Hospital Warangal, \\ Telangana state \\ *Corresponding Author \\ Dr Dodda Prasad Reddy \\ Lakshmi Narsimha Nursing Home, Nehru Centre, Mahabubabad, Warnagal-506101, Telangana state
}

\begin{abstract}
Distal femoral fractures are difficult to manage because they are involved with extensive soft tissue injuries, comminution, and involvement of articular surface. There are several implants used to treat includes condylar buttress plate fixation, locking compression plate, dynamic condylar screw, and cancellous screws.

Methods: Kakatiya Medical College and MGM Hospital, Warangal. A total of $n=25$ patients were studied during the period of which in $n=23$ patients mode of injury was due to road traffic accidents [RTA] and the remaining 2 cases are due to slip and fall. They there are $n=23$ compound fractures (80\%) and among them, $n=1$ case belongs to type I, $n=2$ cases classified under type II and remaining are type III (80\%). During follow up, those patients who visited the outpatient department once in every four weeks assessed fracture union clinically and radiologically and the range of motion of knee and power of quadriceps was also assessed. At the end of 12 weeks, partial weight-bearing was allowed with the help of axillary crutches or walker and full weight-bearing was allowed at the end of 4months after confirming the clinical and radiological union of the fracture.

Results: The majority of the study subjects $n=20(80 \%)$ had Range of knee flexion up to 80 degrees of knee flexion range of movement. More than 80 degrees of motion was found in $n=5(20 \%)$ of the subjects shown in table 6. Most $n=11(44 \%)$ of the study population were found to have excellent NEER'S score followed by good $n=9(36 \%)$ and fair with $n=3(12 \%)$, failure $n=2(8 \%)$ NEERs score was found to be least in our study.

Conclusion: An analysis of results of the present study based on the type of fractures shows good results were seen with Muller's type B fractures than type $C$. The younger individuals aged less than 18-38 years had better functional outcome when compared to the elderly patients. Among the different implants used for fixation of fractures in the present study, CBP was found to be the best choice as compared to other implants.

Keywords: Intra Articular Fractures, Distal Femoral Fractures, Functional Outcome.
\end{abstract}




\section{Introduction}

Distal femoral fractures account for $4-7 \%$ of all femoral fractures. $31 \%$ of femoral fractures involves distal portion excluding the hip fractures (1). Incidence of supracondylar fractures of femur has shown bimodial age distribution with high incidence in young ages and elderly. In young the fractures increased due to RTA and in elderly it is due to minor falls ${ }^{[2]}$. They are often unstable and comminuted with intra articular extension and associated with severe soft tissue damage, injury to the quadriceps mechanism and ligament disruption of knee joint .They may be associated with fractures of femoral neck, shaft, acetabulum, patella, tibial condyle and tibia shaft. Associated ligamentous injury of knee has been reported in $20 \%$ cases ${ }^{(3)}$.The presence of extensive comminution often presents difficulty to the surgeon to provide good functional outcome. The goal of any treatment is to maintain or restore the congruity of the articular surface and restore the length and alignment of the femur and subsequently the function of limb. Although decades ago, conservative management was an option in treating such fractures, presently surgical management clearly gives a better outcome in most scenarios. These are complex injuries which have been treated by different methods. Closed reduction as described by Watson Jones and John Charnley led to stiffness, angular deformities or shortening and needed prolonged confinement to bed. This prompted most surgeons to indulge in more aggressive treatment through open reduction and internal fixation. Surgical fixation allows early mobilization and knee range of motion, better union rates, earlier weight bearing and return to baseline activities.

\section{Material and Methods}

This is a prospective observational study was done in the Department of Orthopedics, Kakatiya Medical college and MGM hospital, Warangal. Institutional Ethical committee permission was obtained for the study. Written consent was obtained from all the participants of the study.
Inclusion criteria were all the adult male patients with intraarticular distal femoral fractures. Exclusion criteria were patients with severe polytrauma, Associated with fractures of the skull, fractures of spine and patients with malignancy. A total of $n=25$ patients were studied during the period of which in $n=23$ patients mode of injury was due to road traffic accidents [RTA] and the remaining 2 cases are due to slip and fall. They there are $n=23$ compound fractures $(80 \%)$ and among them, $n=1$ case belongs to type $I, n=2$ cases classified under type II and remaining are type III (80\%). All patients were immediately admitted and in detail general examination done for a complete assessment of the status of body functioning systems like head, spine, chest, abdomen, pelvis, and limb. Patients who are suffering from severe blood loss and hypovolemic shock was corrected with venous fluids and blood. Any case of head and chest injuries and blunt injury abdomen got referred to Neurosurgeon's and Cardiothoracic surgeons and General surgery doctors for further treatment in standard guidelines. After resuscitation, the period was over, if the patient was hemodynamically stable then the patient was shifted to the X-ray department and taken proper AP and LATERAL view of the affected limb. With the help of X-rays, the diagnosis was made and classified according to Muller's classification (4). In the case of compound fracture, grading was given according to Gustilos classification, wounds are debrided thoroughly and clean with saline, hydrogen peroxide, betadine and if the wound was smaller primary closure was done. Plastic surgery intervention needed for SSG and flap cover. All compound fractures are covered with injection TT, and combinations of antibiotics consist of cephalosporin, aminoglycosides, and metronidazole and this regimen effectively prevented infection. For all the fractures antibiotic regimen was started 12 hours before surgery and continued for $5^{\text {th }}$ to $7^{\text {th }}$ post-operative day. If the patient general condition is stable then they are fit for general or spinal anesthesia and taken up for 
surgery. If a patient is more than 40 years, necessary preoperatively evaluation of the cardiac status with ECG, Chest X-ray, and 2D ECHO if necessary 2D ECHO was done. For the posted case of distal femoral fracture for surgery, internal fixation was done through the lateral incision just anterior to the intermuscular septum, for condylar buttress plate and locking plate. All cases were done under spinal anesthesia in the operation theatre of NIMS. Image intensifier was used where ever necessary. The implants used are Condylar Buttress Plate [CBP], Locking Compression Plate [LCP], Cancellous Screw Fixation $[\mathrm{CSF}]$ and external fixator and Ilizarov fixator. Both cortical and cancellous bone grafting was done from iliac crest and fibula for severely comminuted metaphyseal and Intraarticular fractures and all Bone grafting were done along with primary operation.

Postoperatively the patient was kept in postoperative ward for 24 hours and then shifted to the respective general ward. On the second postoperative day, the wound was dressed and the drain was removed. Post-operative check X-ray was taken. Assisted quadriceps exercises were started from $2^{\text {nd }}$ postoperative day and knee range was started after 3 weeks. Suture removal was done on $11^{\text {th }}$ post-operative day, and the patient was discharged with the advice of strict no weight-bearing and active quadriceps exercises and asked to come to the hospital after 4 weeks. Knee brace for some patients and above knee cylinder cast for some patients for 4 weeks is given. During follow up, those patients who visited the outpatient department once in every four weeks assessed fracture union clinically and radiologically and the range of motion of knee and power of quadriceps was also assessed. At the end of 12 weeks partial weight-bearing was allowed with the help of axillary crutches or walker and full weight-bearing was allowed at the end of 4months after confirming the clinical and radiological union of the fracture.
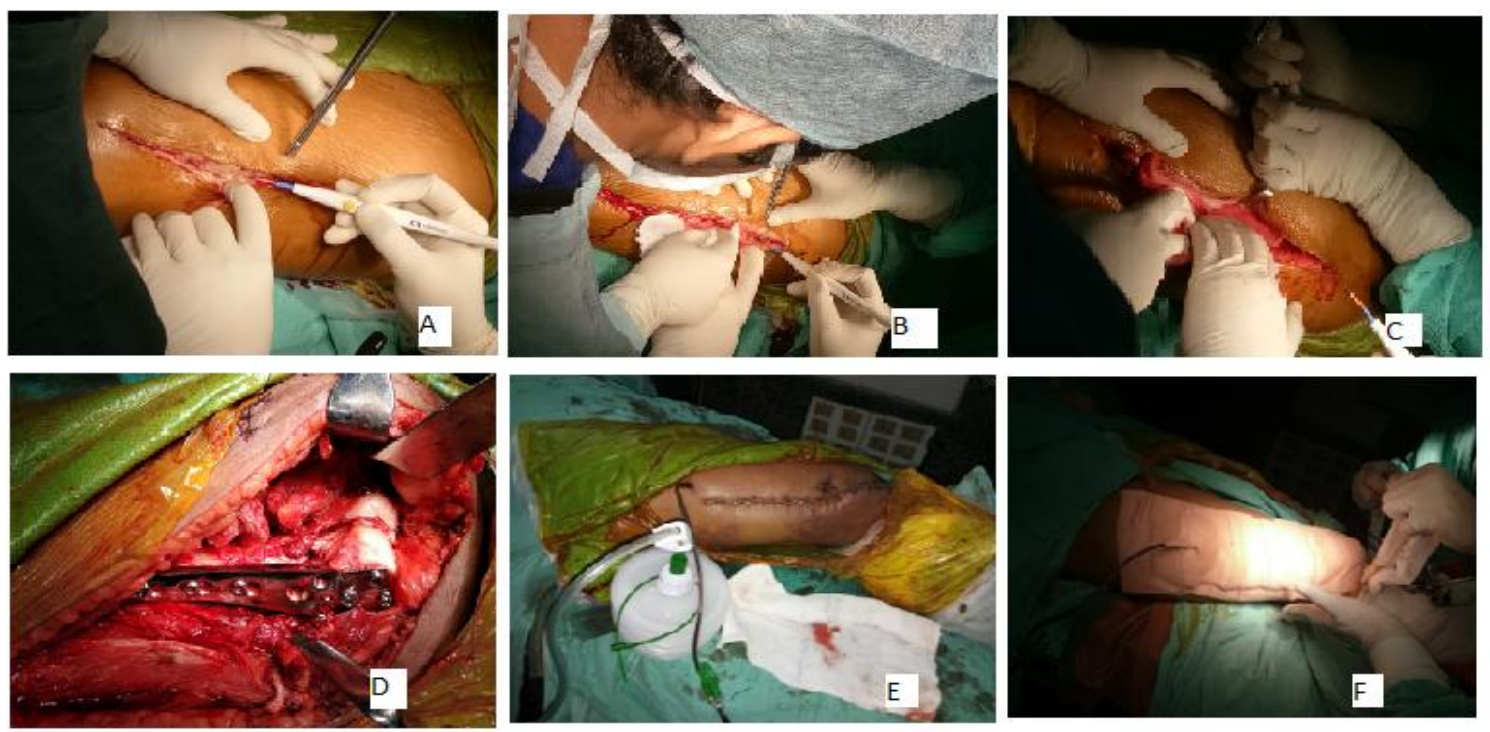

Figure 1: A: skin incision; B: the splitting of Iliotibial band; C: Elevation of Vastus Lateralis; D: Exposure of articular surface with reduction of condyle with the bone holder with placing the plate; $\mathbf{E} \boldsymbol{\&} \mathbf{F}$ : shows wound closure

\section{Results}

The most common age group involved in the fractures was 29-38 years followed by $39-48$ years. The mean age group among the study population was 36 years with a range of $52(18-70$ years) table 1. Among study participants, 23 patients sustained an injury due to RTA and 2 patients sustained an injury due to fall. Most of the cases in the present study were belonging to Muller's Class C3 $\mathrm{n}=14(56 \%)$ followed by C2 
$\mathrm{n}=4(16 \%), \mathrm{B} 2 \mathrm{n}=3(12 \%)$ and other distribution is shown in table 2 .

Table 1: Distribution of cases in the present study

\begin{tabular}{|l|c|c|}
\hline $\begin{array}{l}\text { AGE group } \\
\text { (years) }\end{array}$ & $\begin{array}{c}\text { Number } \\
\text { (N) }\end{array}$ & $\begin{array}{c}\text { Percentage } \\
(\%)\end{array}$ \\
\hline $\mathbf{1 8}$ to 28 & 6 & 24 \\
\hline $\mathbf{2 9}$ to 38 & 9 & 36 \\
\hline $\mathbf{3 9}$ to 48 & 8 & 32 \\
\hline $\mathbf{4 9}$ to 58 & 1 & 4 \\
\hline$>\mathbf{5 8}$ & 1 & 4 \\
\hline Total & 25 & 100 \\
\hline
\end{tabular}

Table 2: Distribution of study population as per Muller's Classification ${ }^{(4)}$

\begin{tabular}{|l|c|c|}
\hline $\begin{array}{l}\text { Group of Fracture } \\
\text { (Muller's Classification) }\end{array}$ & $\begin{array}{c}\text { Number } \\
(\mathbf{N})\end{array}$ & $\begin{array}{c}\text { Percentage } \\
(\mathbf{\%})\end{array}$ \\
\hline B1 & 1 & 4 \\
\hline B2 & 3 & 12 \\
\hline B3 & 2 & 8 \\
\hline C1 & 1 & 4 \\
\hline C2 & 4 & 16 \\
\hline C3 & 14 & 56 \\
\hline Total & 25 & 100 \\
\hline
\end{tabular}

Among the study population, the majority of the patients $\mathrm{n}=18 \quad(72 \%)$ sustained intra-articular distal femoral fracture only and there were no associated injuries. Proximal both bones fracture alone (4\%) was the least associated injury. Patellar fractures, proximal tibial fractures and Proximal both bone fracture + patellar fracture were seen in $n=2(8 \%)$ each shown in table 3 .

Table 3: Distribution of associated injuries in the study population

\begin{tabular}{|l|c|c|}
\hline Associated Injuries & $\begin{array}{c}\text { Number } \\
(\mathbf{N})\end{array}$ & $\begin{array}{c}\text { Percentage } \\
(\%)\end{array}$ \\
\hline Patellar fracture bones & 2 & 8 \\
\hline $\begin{array}{l}\text { Proximal both } \\
\text { fracture }\end{array}$ & 2 & 4 \\
\hline Proximal tibia fracture & 2 & 8 \\
\hline $\begin{array}{l}\text { Proximal both bone } \\
\text { racture + patellar fracture }\end{array}$ & 18 & 72 \\
\hline Nil & 25 & 100 \\
\hline Total
\end{tabular}

The initial management was done in the patients before the definitive management was initiated. Among the study group, most of the patients (88\%) were managed initially by above knee slab alone followed by a combination of debridement and above knee slab (8\%) shown in figure 2.

\section{Initial management (N\%)}

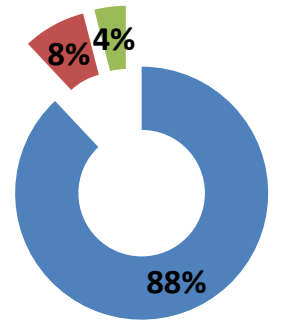

above knee slab

debridement \& above knee slab

debridement\& external fixator
Figure 2: Showing the initial management in the cases

The definitive management was done using various implants; the implants used are Condylar Buttress Plate [CBP], Locking Compression Plate [LCP], Cancellous Screw Fixation [CSF]. Most of the patients were fixed with condylar buttress plate $n=11(44 \%)$, LCP with fibular grafting was done in $\mathrm{n}=3(12 \%)$, Cancellous screw fixation was done in $\mathrm{n}=2(8 \%)$, Debridement spanning fixator and rush nail were used in $n=9(36 \%)$ of patients shown in table 4.

Table 4: Distribution of the study population with the definitive treatment

\begin{tabular}{|l|c|c|}
\hline Definitive Treatment & $\begin{array}{c}\text { Number } \\
(\mathbf{N})\end{array}$ & $\begin{array}{c}\text { Percentage } \\
(\boldsymbol{\%})\end{array}$ \\
\hline CBP & 11 & 44 \\
\hline LCP with fibular grafting & 3 & 12 \\
\hline CSF & 2 & 8 \\
\hline $\begin{array}{l}\text { Debridement + Spanning } \\
\text { Fixator + Rush Nail }\end{array}$ & 9 & 36 \\
\hline Total & 25 & 100 \\
\hline
\end{tabular}

Among the study population, the patients treated with CBP were found to have radiological union by 12 to 18 week (44\%), followed by the patients treated with Debridement with spanning fixator and rush nail (20\%) who were found to have radiological union by 19 to 25 weeks, indicating that most of the condylar buttress plate (CBP) treated patients had early union than the other methods association between them was found to be significant the overall union is described in table 5. 
Table 5: Distribution of union of fractures in weeks

\begin{tabular}{|l|c|c|}
\hline Union (In Weeks) & $\begin{array}{c}\text { Number } \\
(\mathbf{N})\end{array}$ & $\begin{array}{c}\text { Percentage } \\
(\boldsymbol{\%})\end{array}$ \\
\hline $\mathbf{1 2}$ to 18 weeks & 20 & 80 \\
\hline 19 to 25 weeks & 5 & 20 \\
\hline Total & 25 & 100 \\
\hline
\end{tabular}

The majority of the study subjects $n=20(80 \%)$ had Range of knee flexion up to 80 degrees of knee flexion range of movement. More than 80 degrees of motion was found in $n=5(20 \%)$ of the subjects shown in table 6 . Most $n=11(44 \%)$ of the study population were found to have excellent NEER'S score followed by good $n=9(36 \%)$ and fair with $\mathrm{n}=3$ (12\%), failure $\mathrm{n}=2(8 \%)$ NEERs score was found to be least in our study given in table 7 .

Table 6: Distribution of the Range of movementknee flexion

\begin{tabular}{|l|c|c|}
\hline ROM OF KNEE & $\begin{array}{c}\text { Number } \\
(\mathbf{N})\end{array}$ & $\begin{array}{c}\text { Percentage } \\
(\mathbf{\%})\end{array}$ \\
\hline $\begin{array}{l}\text { Less than or equal to } 80 \\
\text { degrees }\end{array}$ & 20 & 80 \\
\hline More than 80 degrees & 5 & 20 \\
\hline Total & 25 & 100 \\
\hline
\end{tabular}

Table 7: Distribution of study population based on NEER'S Score

\begin{tabular}{|l|c|c|}
\hline NEER'S SCORE & $\begin{array}{c}\text { Number } \\
(\mathbf{N})\end{array}$ & $\begin{array}{c}\text { Percentage } \\
(\mathbf{\%})\end{array}$ \\
\hline Excellent (>85) & 11 & 44 \\
\hline Good (70-85) & 9 & 36 \\
\hline Fair (55-69) & 3 & 12 \\
\hline Failure (<55) & 2 & 8 \\
\hline Total & 25 & 100 \\
\hline
\end{tabular}

In the present study, we found only $n=2(8 \%)$ of populations were found to have a complication in form of infection they have managed appropriately with antibiotics and resulted in the complete resolution of the infections. whereas $92 \%$ of study populations had no complications shown in table 8.

Table 8: Distribution of the complications

\begin{tabular}{|l|c|c|}
\hline Complication & $\begin{array}{c}\text { Number } \\
(\mathbf{N})\end{array}$ & $\begin{array}{c}\text { Percentage } \\
(\boldsymbol{\%})\end{array}$ \\
\hline Infection & 2 & 8 \\
\hline Nil & 23 & 92 \\
\hline Total & 25 & 100 \\
\hline
\end{tabular}

\section{Discussion}

Distal femoral fractures are difficult to treat because they are often unstable and comminuted and have a potential for long term disability. Varus collapse, malunion and nonunion were the problems before fixed angle plates and indirect reduction techniques were introduced. In principle, therefore, all intra - articular distal femoral fractures should be treated surgically. Successful treatments of distal femoral fractures require surgery and maintenance of the congruence of the articular surfaces. The prognostic factor for supracondylar fracture includes age, intra articular involvement, method of treatment, timing of joint mobilization etc. Comparison of results with other studies is often difficult because of difference in the classifications schemes and the use of different methods of treatment ${ }^{[5-7]}$. Some articles have been published documenting superior functional results using internal fixation ${ }^{[8,9]}$. Rigid fixation has also enabled earlier knee motion and weight bearing, which help prevent some of the serious complication attributed to prolonged bed rest and traction ${ }^{[5,6]}$. In our study an attempt was made to assess the factors affecting functional outcome of distal femoral fractures with intra articular extension, treated by various surgical methods. The present study was conducted on 25 patients with supracondylar fracture with intra articular extension admitted in department of Orthopedics, in MGM Warangal, Hospital.

In our study age distribution shows majority (92\%) of patients were in the age group of 18 to 48 years. The maximum age of the patient in the present study was 70 years and minimum being 18 years, with mean age of 27.50 years .This reflects that young and active individuals are prone to this fracture due to high velocity injuries. The average age was less than (40 years) compared to other reported series ${ }^{[10]}$. The present showed that there is high preponderance of males in this kind of fractures the same was observed by Siliski et al; [9]. The male preponderance has been attributed to a reason of more outgoing personality and thus 
high rate of incidence of road traffic accidents amongst them. Most common cause of injury in our study was road traffic accidents Tapi Nalo et al; ${ }^{[11]}$ in their study found out of 30 patents, 23 were males and 7 were females. In our study we found $80 \%$ of patients had right side involved and left side in $20 \%$ these findings are commensurate with findings of Abhijit Sarkar et al: ${ }^{[12]}$. In our study the fractures were classified based on AO classification, type C (19) fractures are common comparative to type B (06). In type C, type C3 (14) fractures are predominant fractures because of complex pattern of fracture and associated severity of injuries. According to Schatzker et al;

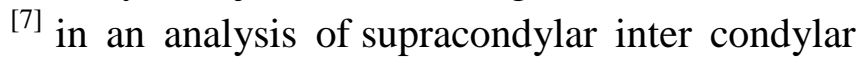
fracture femur, $74 \%$ had better results in typeC. The average hospitalization time in our study was 10.2 days. Stewart et al; ${ }^{[6]}$ reported hospitalization for 20 days.

In our study, 5 patents (20\%) had more than 90 degree of knee flexion and most of the patients $\mathrm{n}=20(80 \%)$ had 80 degrees. Knee range of movements more in younger (40yr) patients compared to older age. Knee range of movements better in type $\mathrm{B}$ fracture compared to type $\mathrm{C}$ fractures. The minimum flexion obtained was $40^{\circ}$ and maximum being $100^{\circ}$. In our study average knee range of motion is $80.2 \%$. In our study population, majority of patients treated with CBP, had range of movements equal to 80 degrees. The average post-operative active range of motion as reported by Seinsheimer et al; ${ }^{[12]}$ was 91 degrees. Weight et al; ${ }^{[13]}$ found the average range of knee motion was $5^{\circ}$ to $114^{\circ}$. Slightly lower levels of ROM are seen in this study due to complex pattern of fractures and severe comminution along with articular impaction and bone loss. In majority of the patients, union occurred between 12 to 18 weeks and has excellent Neer's score in 24\% cases. The time taken for union in our study ranged from 12 weeks to 22 weeks with a mean of 13.5 weeks. A Comparative other study, A study by Krishna et al; ${ }^{[14]}$ showed that average duration of radiological union was 15.36 weeks . Similarly in the study conducted by Malik A et al; ${ }^{[15]}$ showed that $96 \%$ of patients achieved radiological union by 20 weeks and $100 \%$ achieved union by 24 to 36 weeks of follow up. According to Tapi Nalo et al $;^{[11]}$ Clinical union was seen at a meantime of 14.47 weeks (range, 932 weeks). Radiologically, bridging callus was seen at 12-16 post-operative weeks and the mean time to complete radiological union was 26.47 weeks (range, 20-40 weeks). Weight et al; ${ }^{[13]}$ found it to be 13 weeks, Kregor et al; ${ }^{[16]}$ found it to be 12 weeks. In this study there were 23 (92\%) open fractures, $16(64 \%)$ of them were treated with open reduction and internal fixation and 07 cases were external fixator used. Open reduction and internal fixation gave better results than external fixation. Of these internal fixations; CBP gave better results than other internal fixation. Our results are comparable with the results of a study conducted by John M. Siliski et al; where $40 \%$ were open fractures, with $40 \%$ good results, and the rest poor ${ }^{[9]}$. They also had the conclusion that rigid internal fixation is far superior to external fixation even in open fractures.

\section{Conclusion}

An analysis of results of present study based on the type of fractures shows good results were seen with Muller's type B fractures than type C. The younger individuals aged less than 18-38 years had better functional outcome when compared to the elderly patients. Among the different implants used for fixation of fractures in the present study CBP was found to be best choice as compared to other implants.

\section{Conflict of interest: None \\ Source of support: Nil \\ Ethical Permission: Obtained}

\section{References}

1. Areneson TJ, Melton LJ, Lewallen DG, et al. Epidemiology of diaphyseal and distal femoral fractures in Rochester, Minnesota,1965-1984.Clin Orthop Relat Res 1988;234:188-94. 
2. Martinet $\mathrm{O}$, Cordey $\mathrm{J}$, Harder $\mathrm{Y}$, et al (2000). The epidemiology of fractures of the distal femur. Injury 2000; 31 Suppl 3: C62-63.

3. Walling AK, Seradge H, Speigel PG. Injuries to the knee ligaments with fractures of the femur. J Bone Joint Surg Am 1982; 64: 1324-27.

4. Muller, M.E.; Nazarian, S.; Koch, P. Classification AO des Fractures. SpringerVerlag New York,1987.

5. Neer CS II, Grantham SA, Shelton ML. Supracondylar Fracture of the. Adult Femur -A Study of One Hundred and Ten Cases. JBJS Am1967 June; 49-A (4): 59113.

6. Stewart MJ, Sisk TD, Wallace SL Jr. Fractures of the Distal Third of Femur - A Comparison of methods of treatment. JBJS Am 1966 June; 48-A(4): 784-80.

7. Schatzker J, Home G, Waddell J. The Toronto Experience with Supracondylar Fractures of Femur. Injury 1974 Nov; 6(2): 113-128.

8. Muller, M.E. Allgower, M.; Schneider, R. Willenegger, $H$. Manual of Internal Fixation, 3rd Ed. New York, SpringerVerlag, 1991.

9. Siliski JM, Mahring $\mathrm{M}$ and Hofer $\mathrm{Hp}$ Supracondylar-intercondylar fractures of the femur. Treatment by internal fixation. J Bone Joint Surg Am. 1989; 71:95-104.

10. Healy WL, Brooker AF. Distal femoral fractures comparisons of open and closed methods of treatment. Clinical Orthopaedics and related research 1983; 174:200-206.

11. Tapi Nalo, Amit Agrahari, Snehasish Datta, Vinil Paul S, Nongthon Singh, Roel Langshong. Treatment of Supracondylar Fracture of Distal Femur with Condylar Locking Compression Plating, IJSR, 2015; 4(2):1468-70.
12. Abhijit Sarkar, Sachlang Debbarma, Santosh Rehang, Subal Debnath, JM Datta, S Naha. Outcome of Treatment of Distal Third Femur Fracture by Locking Compression Plate MIPPO Technique. Indian Journal of Applied Research.2016; 6(3): 271-74.

13. Weight M, Collinge C. Early results of the less invasive stabilization system for mechanically unstable fractures of the distal femur (AO/OTA types A2, A3, C2, and C3). J Orthop Trauma 2004;18(8): 503-508.

14. Krishna KR, Nayak B, Amrit G. Study of surgical management of distal femoral fractures by distal femoral locking compression plate osteosynthesis. Indian Journal of Orthopaedics Surgery 2015; 1(1): 22-26.

15. Adnan L M, Mudassar S, Noman S N, Suhail NKN. Outcome of Locking Compression Plate in Supracondylar Fracture of Distal Femur by Minimally Invasive Plate Osteosynthesis. P J M H S 2015;9(1): 31-33.

16. Kregor PJ, Stannard JA, Zlowodzki M, Cole PA. Treatment of distal femur fractures using the less invasive stabilization system: surgical experience and early clinical results in 103 fractures. J Orthop Trauma 2004; (8): 509-20. 